Original

\title{
A study of the effects of phenolic de-emulsifier solutions in xylene on the de-emulsification of a Nigerian crude oil emulsion
}

\author{
Vincent Enontiemonria Efeovbokhan ${ }^{\mathrm{a}, *}$, Joseph Denis Udonne ${ }^{\mathrm{b}}$, Ayodedji Adedeji Ayoola ${ }^{\mathrm{a}}$, \\ Oluwadara Temitayo Shogbamu ${ }^{\mathrm{a}}$, Rasheed Babalola ${ }^{\mathrm{c}}$ \\ ${ }^{a}$ Department of Chemical Engineering, Covenant University, Ota, Nigeria \\ ${ }^{\mathrm{b}}$ Department of Chemical Engineering and Polymer, Lagos State University, Lagos, Nigeria \\ ${ }^{\mathrm{c}}$ Akwa Ibom State University, Ikot Akpaden, Nigeria
}

Received 8 June 2016; accepted 17 January 2017

Available online 11 March 2017

\begin{abstract}
The research and development of de-emulsifiers for separating water from crude oil emulsions usually result in varying degrees of success, depending on the location and the type of crude being treated. This makes de-emulsifiers crude oil specific and thus gives rise to the continuous search for more and effective de-emulsifiers that can meet the specific needs of each locality. In this study, base-catalyzed phenol formaldehyde resins were formulated at varying formaldehyde to phenol ratios (1.2:1-1.8:1); the assessment was carried out by the bottle test method at varied de-emulsifier concentrations ( vol/vol) in xylene acting as solvent diluent. The bottle test was carried out at an optimum temperature of $70{ }^{\circ} \mathrm{C}$, dosage of $50 \mathrm{ppm}$ and residence times of 10 and $20 \mathrm{~min}$. A factorial design was done to determine the best combination of the de-emulsification conditions for the resolution of the Nigerian crude oil emulsion. The results were analyzed and optimized using Minitab 16 utilizing a Pareto chart, normal effects, main effects and interaction plots. From the analysis carried out, it was found that the most effective formulated de-emulsifier was obtained at formaldehyde to phenol (F:P) mole ratio of 1.8:1, 80\% de-emulsifier concentration in xylene and residence time of 20 min. This de-emulsifier obtained a water separation efficiency of $79 \%$ compared to the commercial de-emulsifier which gave $71 \%$ efficiency. Thus the solution of P:F de-emulsifiers in xylene enhances the de-emulsification of the Nigerian crude oil emulsions.

(C) 2017 Universidad Nacional Autónoma de México, Centro de Ciencias Aplicadas y Desarrollo Tecnológico. This is an open access article under the CC BY-NC-ND license (http://creativecommons.org/licenses/by-nc-nd/4.0/).
\end{abstract}

Keywords: Resins; Diluent; Emulsion; De-emulsification; Xylene; Crude oil

\section{Introduction}

With a maximum crude oil production capacity of 2.5 million barrels per day, Nigeria ranks as Africa's largest producer of crude oil and the sixth largest oil producing country in the world; this makes the country important to the world's energy market (NNPC, 2015). Crude oil is a naturally occurring mixture, consisting predominantly of hydrocarbons, sulphur, nitrogen and

\footnotetext{
* Corresponding author at: Department of Chemical Engineering, College of Engineering, Covenant University, Km 10 Idiroko Road, Ota, Ogun State, Nigeria.

E-mail address: vincent.efeovbokhan@ covenantuniversity.edu.ng (V.E. Efeovbokhan).
}

Peer Review under the responsibility of Universidad Nacional Autónoma de México. metals (Yasin et al., 2013). The ever-increasing chemical utilization of crude oils and petroleum products calls for a better knowledge of the composition, structure and properties of their fractions. Parameters often determined in crude oil include: density, API gravity, pour point, kinematic viscosity, percentage water content, salt content, sulphur content, asphaltene content, ASTM distillation cracking point as well as metal/mineral contents. Crude oil blends obtained from Nigeria contain low sulphur content and are referred to as light (or sweet) crude oil (Oyekunle \& Famakin, 2004; Dickson \& Udoessien, 2012). Their physico-chemical parameters revealed that it contains both salts and heavy metals, namely: $\mathrm{Zn}, \mathrm{Pb}, \mathrm{Mn}, \mathrm{Co}, \mathrm{Cd}, \mathrm{Fe}, \mathrm{Ni}, \mathrm{Cr}$ and V (Dickson \& Udoessien, 2012). These parameters help to predict and identify the behavior of the crude oil blends and the finished petroleum products (Yasin et al., 2013). Crude oil is the basic raw material for the refining industries, which in 
turn determines the quality of petroleum products - a key determinant of consumer satisfaction and the performance of the refineries (Yasin et al., 2013). Nigerian crude oil samples produced from various locations have been tested and characterized under laboratory conditions using ASTM methods (Akinyemi, Udonne, Efeovbokhan, \& Ayoola, 2016; Yasin et al., 2013). All the tested samples belong to the class of light crude oil on the basis of API gravity. They have been compared with each other and have been found to have low specific gravity, low sulphur contents, low viscosity and low pour point. All the tested samples are of sweet type on the basis of total sulfur contents. The distribution of $n$-alkanes (isoprenoide/ $n$-alkanes ratios) shows that the oil samples originated mainly from terrestrial organic sources deposited in an oxic paleo-environment. The gum content ranges between 6.27 and $45.84 \mathrm{mg} / \mathrm{L}$, cloud point from 3.00 to $12.00^{\circ} \mathrm{C}$, pour point from -7.00 to $4.00{ }^{\circ} \mathrm{C}$ and flash point is $<30.00^{\circ} \mathrm{C}$. The moisture content or water cut varies from $0.13 \%$ to $60 \%$ (Djuve, Yang, Fjellanger, Sjoblom, \& Pelizzetti, 2001; Onojake, Osuji, \& Oforka, 2013). The high water content (or the presence of emulsion) in the Nigerian crude oil is inimical to the quality of petroleum products and it is one major challenge confronting the production of internationally acceptable crude oil of high quality. It is reported for instance, that crude oil from one of Nigeria's oil fields in Obagi, Port Harcourt, contains between $2 \%$ and $12 \%$ basic sediment and water (BS and W), which is by far higher than the required specification of $0.5 \%$, (Efeovbokhan, Olayemi, Anawe, \& Abatan, 2015). This problem if not addressed, affects the market value of crude oil in the international market. Water-in-oil emulsion is formed during oil production and its stability varies a lot. The presence of water or emulsion comes with undesirable consequences including an increase in the unit cost of oil production and processing, distortions in the physical characteristics of the oil, such as the density, viscosity, high-pressure drops in flow lines, corrosion, rise in conductivity and leaching of additives (Becher, 1985; Tambe \& Sharma, 1993). The produced water must be separated from the oil, treated, and adequately disposed of. The emulsion stability varies with time depending on the nature and properties of the crude oil (Bhardwaj \& Hartland, 1998). The presence of crude oil emulsions in the refining, processing and production phases is a major challenge all over the world (Grace, 1992); and this challenge has attracted attention from researchers and scholars over the past decades, as a significant portion of the world's crude oil is produced in the form of emulsion. Emulsion is a dispersion of one liquid in another liquid which is immiscible. Crude oil emulsions are formed when oil and water come in contact with each other, coupled with the presence of emulsifying agents like asphaltenes and resins, among others (Kokal, Al-Yousif, \& Meeranpillai, 2001).

De-emulsification (the focus of this research) is the breaking of crude oil emulsions into two clear immiscible phases, i.e., oil and water phases. There are four main methods: mechanical, chemical, electrical and thermal; however, chemical de-emulsification is basically the most suitable way to break crude oil emulsions from the operational and financial point of view, (Selvarajan et al., 2001). This is done by treating the emulsions with chemicals known as de-emulsifiers under varying concentrations and temperatures. These chemicals are specially designed to act on the oil/water interface when they are added to the emulsion. They are very economical and efficient in breaking stable emulsions into clear water and oil phases (Staiss, Bohm, \& Kupfer, 1991). De-emulsifiers aid the separation of oil from water usually at low dosages. Some de-emulsifiers are polymers; others have structures similar to non-ionic emulsifiers. De-emulsifiers are surfactants that are vital in separating the emulsion system (Aske, 2002). The separation rate of water-inoil emulsion usually depends on the type of de-emulsifier used, the stability of the emulsion, temperature of de-emulsification, concentration of the de-emulsifier, residence time and the agitation energy of the de-emulsification process (Sunil, 2006). Some de-emulsifiers that have been suggested for de-emulsification of crude oil emulsion include organic chemicals mostly surfactants such as nonylphenolethoxylate derivatives (Easton \& Thomas, 1989), epoxy resins, polyamines (Myers, 1992), polyglycol ethers (Sawyer, McCarty, \& Parkin, 1994), polyols, oxylated phenols, e.g., alkanolamine and sulphonates (Porter, 1994). The increasing economic need to break crude oil emulsions by use of these chemicals, and hence, reduce the basic sediment and water (BS and $\mathrm{W}$ ) of the Nigerian crude oil has necessitated the conduction of this research work. Accordingly, this work aims at investigating the effects of the varied percentage solution of phenol-formaldehyde (phenolic)-based de-emulsifiers in xylene on the de-emulsification of the Nigerian crude oil emulsion sample.

\section{Material and methods}

\subsection{Materials}

The crude oil emulsion sample used was obtained from an onshore oil field in Port Harcourt, Rivers State, Nigeria. The various chemicals used include: phenol crystals $(99 \%$ purity, technical grade), formaldehyde (37\% purity, Baker analyzed), sodium hydroxide (99\% purity, Riedel-de Haen), sulfuric acid (98\% purity, Sigma-Aldrich analyzed) and xylene $(99.9 \%$ purity; Baker analyzed). All chemicals were used without further purification.

\subsection{Apparatus/equipment}

A batch reactor comprising a $250 \mathrm{ml} 3$-neck flat-bottom flask, to which a reflux condenser and a quick fit thermometer $\left(0-250^{\circ} \mathrm{C}\right.$ range) were mounted, was set up on a hot plate magnetic stirrer (Thermo Scientific, SP 131015 IOWA, USA) inside a fume cupboard (ESCO Ductless). The third neck (opening) on the reactor served as the charging port for the reactants and catalyst. Other equipment used include a pH meter (Jenway, model 3520), a centrifuge machine (Uniscope, model SM800B), graduated centrifuge bottles and a water bath (Uniscope, model SM801A). 


\subsection{Formulation of resoles}

The formulation of resole was done by a poly condensation reaction between formaldehyde and phenol which was catalyzed by sodium hydroxide. The reaction conditions were as follows: For low formaldehyde:phenol (F:P) mole ratio resin (1.2-1.4:1), the reaction was carried out at $90^{\circ} \mathrm{C}$ for $3 \mathrm{~h}$ at $\mathrm{pH}$. The resins in the intermediate $\mathrm{F}: \mathrm{P}$ mole ratio $(1.5: 1)$ were prepared at $80^{\circ} \mathrm{C}$ for $3 \mathrm{~h}$ and $\mathrm{pH} 8$ while the resins in the high $\mathrm{F}: \mathrm{P}$ mole ratio (1.6-1.8:1) were prepared at $60^{\circ} \mathrm{C}$ for $3 \mathrm{~h}$ and $\mathrm{pH}$ 8. The experimental set up was carried out in a fume cupboard. $30 \%$ solution of caustic soda was first prepared. Accurately weighed melted phenol was poured into measured formaldehyde solution in a beaker. The mixture was stirred slowly and the $\mathrm{pH}$ adjusted by adding drops of caustic soda solution until the desired $\mathrm{pH}$ for each reaction was reached. The mixture was poured into a 3neck round bottom flask to which a thermometer and a reflux condenser were attached. The setup was then heated for $3 \mathrm{~h}$ at the desired temperature. The $\mathrm{pH}$ was monitored and adjusted when necessary every $30 \mathrm{~min}$. Uniform agitation was ensured to prevent caking. At the end of the 3-hour period, the reaction mixture was cooled and stored in an appropriately labeled sample bottle. Six different molar ratios of F/P were used in the formulation to examine their effects on the emulsion system. The molar ratios $(\mathrm{F}: \mathrm{P})$ used were $1.2: 1,1.3: 1,1.4: 1,1.5: 1,1.6: 1$, 1.7:1 and 1.8:1. Various percentage solutions $(\mathrm{v} / \mathrm{v})$ of the resin samples (de-emulsifiers) in xylene were then prepared to study their effects on the de-emulsification of the crude oil emulsion system using the bottle test screening method.

\subsection{Basic sediment and water (BS and W) test method}

The method described by Efeovbokhan et al. (2015) was adopted and used for the BS \& W test.

\subsection{Bottle test method}

The method described by Efeovbokhan et al. (2015) was adopted and used for the screening of the various de-emulsifier solutions in the de-emulsification process. It is a physical separation technique employed to separate crude oil emulsions into clear phases of oil and water.

\subsection{Factorial design of experiment}

This is defined as a design of experiment (DOE) which simultaneously studies multiple experimental factors at multiple levels. It is necessary in order to know the optimized value for each de-emulsifier. Using two levels and three factors, the software called "Minitab 16" ran a $2^{3}$ design of experiment table. The three factors are mole ratio of formaldehyde to phenol, residence time and de-emulsifier percentage solution in xylene.

Based on the varied F:P mole ratios, the de-emulsifiers were given code names for ease of reference as seen in Table 1.

The de-emulsifiers were paired to run the $2^{3}$ DOE table. The pairing are de-emulsifier $\mathrm{U}$ and $\mathrm{X}$, de-emulsifier $\mathrm{V}$ and $\mathrm{Y}$,
Table 1

Code names for formulated de-emulsifiers.

\begin{tabular}{lll}
\hline De-emulsifier type & \multicolumn{2}{l}{ Mole ratio } \\
\cline { 2 - 3 } & Formaldehyde & Phenol \\
\hline U & 1.2 & 1 \\
V & 1.3 & 1 \\
W & 1.4 & 1 \\
X & 1.5 & 1 \\
Y & 1.7 & 1 \\
Z & 1.8 & 1 \\
\hline
\end{tabular}

Table 2

Low and high level of factors for de-emulsifier pair $\mathrm{U}$ and $\mathrm{X}$.

\begin{tabular}{lll}
\hline Factors/Terms & \multicolumn{2}{l}{ Variable levels } \\
\cline { 2 - 3 } & $\mathrm{U}$ & $\mathrm{X}$ \\
\hline Residence time (min) (C) & 10 & 20 \\
De-emulsifier \% solution in xylene (B) & 20 & 80 \\
F/P ratio (A) & $1.2: 1$ & $1.5: 1$ \\
\hline
\end{tabular}

de-emulsifier $\mathrm{W}$ and $\mathrm{Z}$. Table 2 shows an example of the two levels of each factor for one of the pairs used.

The full factorial designs were made for all the de-emulsifier pairs using MINITAB 16.

The volume of water in \% was calculated using Eq. (1):

$\%$ water $=\frac{\text { volume of water separated }}{\text { original volume of water in the emulsion }} \times 100$

\section{Results and discussion}

\subsection{Results}

Table 3 (column C8) shows the volume of water separated from a Nigerian crude oil emulsion using all the de-emulsifiers (samples U to Z) at varied concentrations or percentage solution (columns C6), mole ratio (columns C5) and residence times (columns C7). Figs. 1-3 gave the results of screening de-emulsifiers pair $\mathrm{U}$ and $\mathrm{X}$ at $30 / 60 \%, 20 / 80 \%$ and 50/100\% concentrations, respectively. Tables 4 and 5 show the result of the water separated from $2^{3}$ designs at varied concentrations of de-emulsifier pair V \& Y and W \& Z, respectively.

\subsection{Discussion}

\subsubsection{Analysis of formulated de-emulsifiers (samples $U$ to $Z$ )}

3.2.1.1. Pareto chart. Pareto charts (Figs. 1-3) were used to know which factors have statistically significant effects on the response (or volume of water separated). The reference line on the charts helped to indicate which effects were significant. The three figures gave varied results at $\alpha=0.50$. In Figs. 1 and 3 two factors each significantly influenced the de-emulsification process. They include mole ratio (A) and residence time (C) from Fig. 1 while from Fig. 3, they include de-emulsifier concentration (B) and mole ratio (A). From Fig. 2 it was observed that all three factors, de-emulsifier concentration (B), mole ratio 
Table 3

$2^{3}$ design for de-emulsifier $\mathrm{U}$ and $\mathrm{X}$ at different concentrations.

\begin{tabular}{|c|c|c|c|c|c|c|c|c|}
\hline Sample pair & $\begin{array}{l}\mathrm{C} 1 \\
\text { Std order }\end{array}$ & $\begin{array}{l}\mathrm{C} 2 \\
\text { Run order }\end{array}$ & $\begin{array}{l}\mathrm{C} 3 \\
\text { CenterPt }\end{array}$ & $\begin{array}{l}\text { C4 } \\
\text { Blocks }\end{array}$ & $\begin{array}{l}\text { C5 } \\
\text { Mole ratio }\end{array}$ & $\begin{array}{l}\text { C6 } \\
\% \text { Solution }\end{array}$ & $\begin{array}{l}\text { C7 } \\
\text { Residence time }\end{array}$ & $\begin{array}{l}\mathrm{C} 8 \\
\% \text { Volume separated }\end{array}$ \\
\hline \multirow{8}{*}{$\begin{array}{l}\text { De-emulsifier pair } \mathrm{U} \text { and } \mathrm{X} \text { at } \\
30 \text { and } 60 \%\end{array}$} & 2 & 1 & 1 & 1 & 1.5 & 30 & 10 & 14.2 \\
\hline & 4 & 2 & 1 & 1 & 1.5 & 60 & 10 & 19.9 \\
\hline & 8 & 3 & 1 & 1 & 1.5 & 60 & 20 & 36.1 \\
\hline & 3 & 4 & 1 & 1 & 1.2 & 60 & 10 & 10.2 \\
\hline & 6 & 5 & 1 & 1 & 1.5 & 30 & 20 & 28.4 \\
\hline & 1 & 6 & 1 & 1 & 1.2 & 30 & 10 & 7.2 \\
\hline & 7 & 7 & 1 & 1 & 1.2 & 60 & 20 & 16.9 \\
\hline & 5 & 8 & 1 & 1 & 1.2 & 30 & 20 & 12.1 \\
\hline \multirow{8}{*}{$\begin{array}{l}\text { De-emulsifier pair } U \text { and } X \text { at } \\
20 \text { and } 80 \%\end{array}$} & 2 & 1 & 1 & 1 & 1.5 & 20 & 10 & 12.4 \\
\hline & 6 & 2 & 1 & 1 & 1.5 & 80 & 20 & 51.6 \\
\hline & 7 & 3 & 1 & 1 & 1.2 & 80 & 20 & 24.2 \\
\hline & 5 & 4 & 1 & 1 & 1.2 & 20 & 20 & 6.1 \\
\hline & 3 & 5 & 1 & 1 & 1.2 & 80 & 10 & 16.1 \\
\hline & 1 & 6 & 1 & 1 & 1.2 & 20 & 10 & 5.6 \\
\hline & 6 & 7 & 1 & 1 & 1.5 & 20 & 20 & 20.6 \\
\hline & 4 & 8 & 1 & 1 & 1.5 & 80 & 10 & 25.8 \\
\hline \multirow{8}{*}{$\begin{array}{l}\text { De-emulsifier pair } U \text { and } X \text { at } \\
50 \text { and } 100 \%\end{array}$} & 4 & 1 & 1 & 1 & 1.5 & 100 & 10 & 4.6 \\
\hline & 7 & 2 & 1 & 1 & 1.2 & 100 & 20 & 4.8 \\
\hline & 1 & 3 & 1 & 1 & 1.2 & 50 & 10 & 8.9 \\
\hline & 3 & 4 & 1 & 1 & 1.2 & 100 & 10 & 3.2 \\
\hline & 5 & 5 & 1 & 1 & 1.2 & 50 & 20 & 14.5 \\
\hline & 6 & 6 & 1 & 1 & 1.5 & 50 & 20 & 31.0 \\
\hline & 8 & 7 & 1 & 1 & 1.5 & 100 & 20 & 7.7 \\
\hline & 2 & 8 & 1 & 1 & 1.5 & 50 & 10 & 18.6 \\
\hline
\end{tabular}

Pareto chart of the effects (response is volume, alpha $=0.50$ )

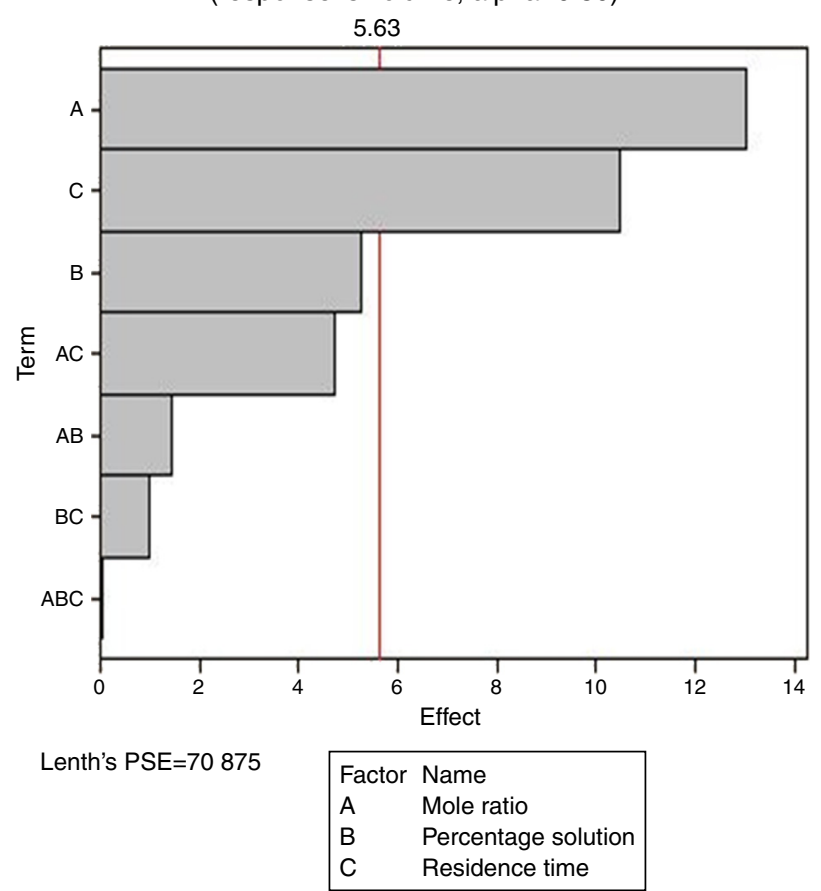

Fig. 1. Pareto plot for de-emulsifier pair $\mathrm{U}$ and $\mathrm{X}$ at 30 and $60 \%$ concentrations.

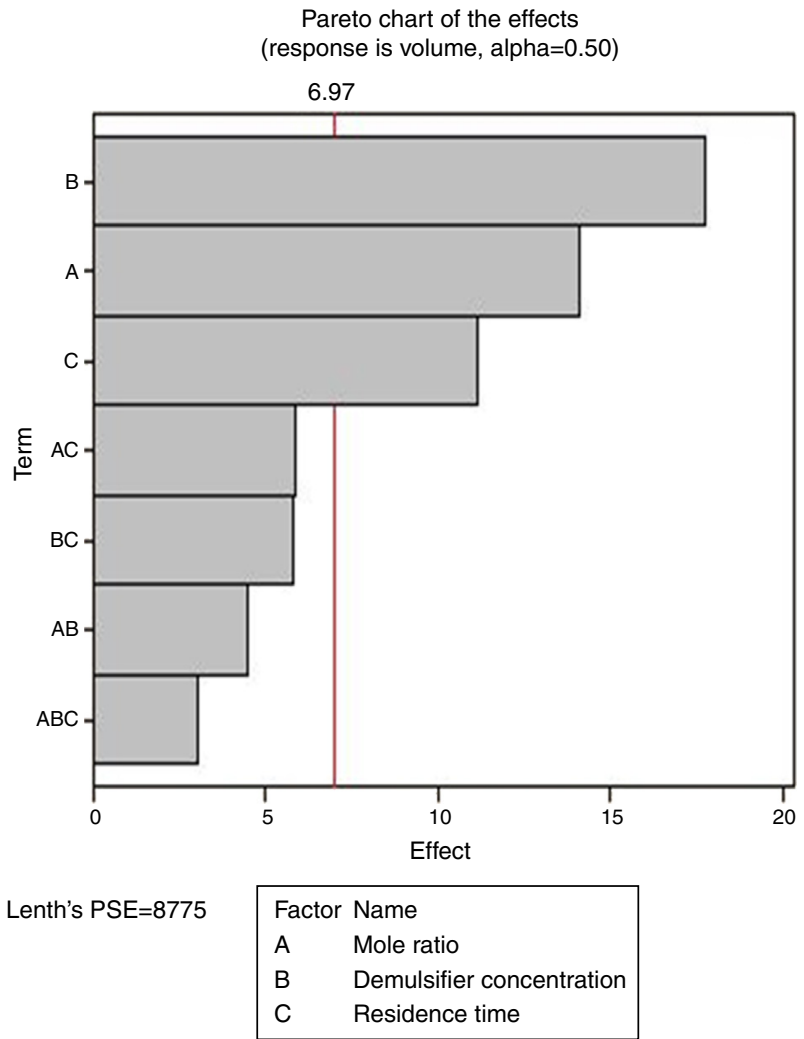

Fig. 2. Pareto plot for de-emulsifier pair $\mathrm{U}$ and $\mathrm{X}$ at 20 and $80 \%$ concentrations. 


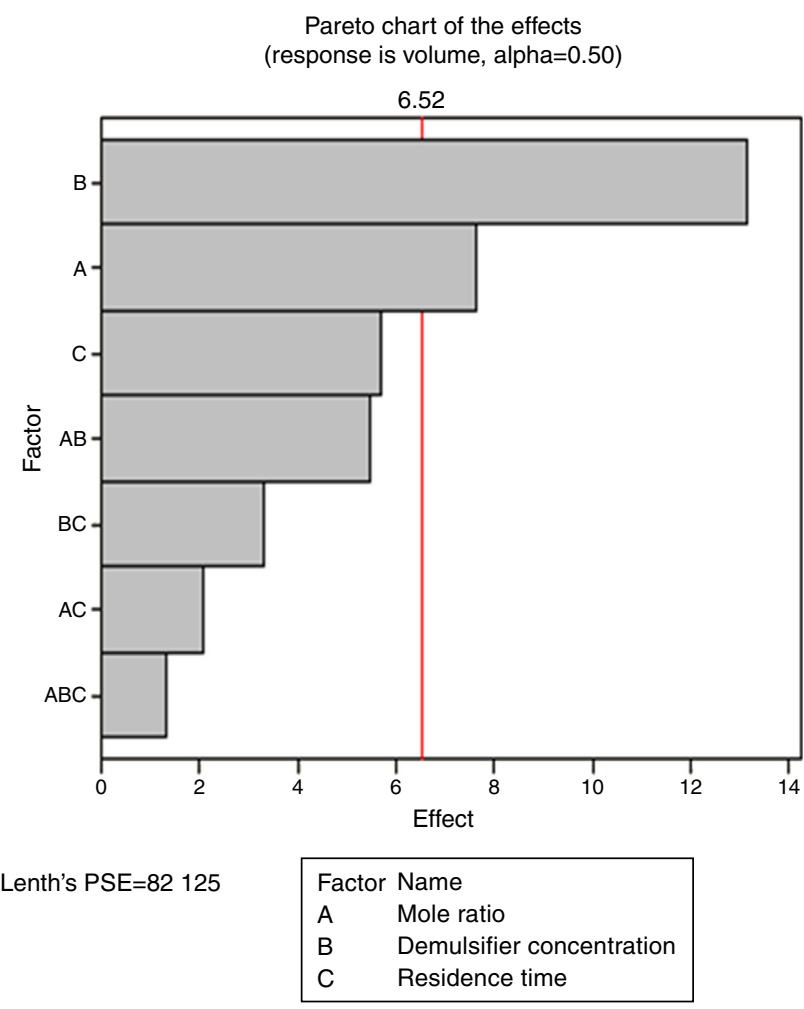

Fig. 3. Pareto plot for de-emulsifier pair $\mathrm{U}$ and $\mathrm{X}$ at 50 and $100 \%$ concentrations.

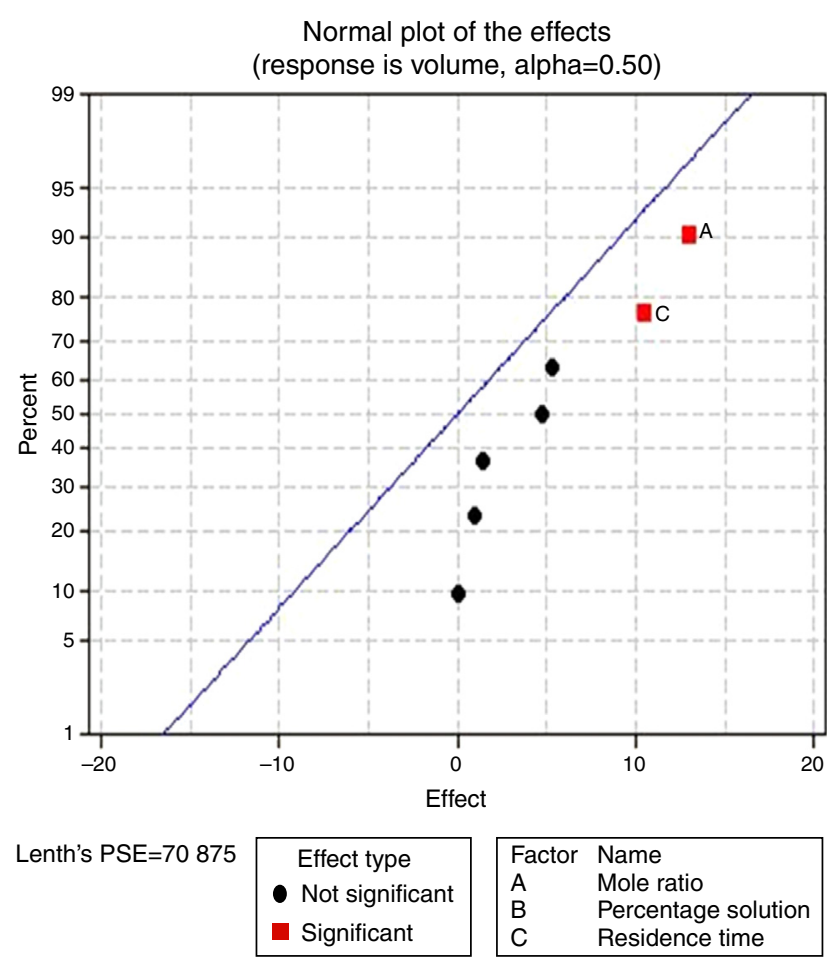

Fig. 4. Normal plot for de-emulsifier pair $\mathrm{U}$ and $\mathrm{X}$ at 30 and $60 \%$ concentrations.

Table 4

$2^{3}$ design for de-emulsifier pair $\mathrm{V}$ and $\mathrm{Y}$ at different concentrations.

\begin{tabular}{|c|c|c|c|c|c|c|c|c|}
\hline Sample pair & $\begin{array}{l}\mathrm{C} 1 \\
\text { Std order }\end{array}$ & $\begin{array}{l}\mathrm{C} 2 \\
\text { Run order }\end{array}$ & $\begin{array}{l}\text { C3 } \\
\text { CenterPt }\end{array}$ & $\begin{array}{l}\text { C4 } \\
\text { Blocks }\end{array}$ & $\begin{array}{l}\text { C5 } \\
\text { Mole ratio }\end{array}$ & $\begin{array}{l}\mathrm{C} 6 \\
\% \text { Solution }\end{array}$ & $\begin{array}{l}\text { C7 } \\
\text { Residence time }\end{array}$ & $\begin{array}{l}\mathrm{C} 8 \\
\% \text { Volume separated }\end{array}$ \\
\hline \multirow{5}{*}{$\begin{array}{l}\text { De-emulsifier pair } \mathrm{V} \text { and } \mathrm{Y} \text { at } \\
30 \text { and } 60 \%\end{array}$} & 2 & 1 & 1 & 1 & 1.7 & 30 & 10 & 22.4 \\
\hline & 1 & 2 & 1 & 1 & 1.3 & 30 & 10 & 10.6 \\
\hline & 7 & 4 & 1 & 1 & 1.3 & 60 & 20 & 24.2 \\
\hline & 4 & 5 & 1 & 1 & 1.7 & 60 & 10 & 28.5 \\
\hline & 8 & 6 & 1 & 1 & 1.7 & 60 & 20 & 47.4 \\
\hline \multirow{5}{*}{$\begin{array}{l}\text { De-emulsifier pair } \mathrm{V} \text { and } \mathrm{Y} \text { at } \\
20 \text { and } 80 \%\end{array}$} & 4 & 1 & 1 & 1 & 1.7 & 20 & 10 & 40.6 \\
\hline & 7 & 2 & 1 & 1 & 1.3 & 80 & 20 & 32.3 \\
\hline & 5 & 3 & 1 & 1 & 1.3 & 80 & 20 & 11.3 \\
\hline & 8 & 4 & 1 & 1 & 1.7 & 20 & 20 & 67.7 \\
\hline & 2 & 5 & 1 & 1 & 1.7 & 80 & 10 & 17.4 \\
\hline 50 and $100 \%$ & 7 & 2 & 1 & 1 & 1.3 & 100 & 20 & 8.1 \\
\hline & 8 & 3 & 1 & 1 & 1.7 & 100 & 20 & 10.2 \\
\hline & 1 & 4 & 1 & 1 & 1.3 & 50 & 10 & 11.6 \\
\hline & 5 & 5 & 1 & 1 & 1.3 & 50 & 20 & 19.4 \\
\hline & 4 & 6 & 1 & 1 & 1.7 & 100 & 10 & 6.1 \\
\hline & 2 & 7 & 1 & 1 & 1.7 & 50 & 10 & 24.4 \\
\hline & 6 & 8 & 1 & 1 & 1.7 & 50 & 20 & 40.6 \\
\hline
\end{tabular}


Table 5

$2^{3}$ design for de-emulsifier pair $\mathrm{W}$ and $\mathrm{Z}$ at different concentrations.

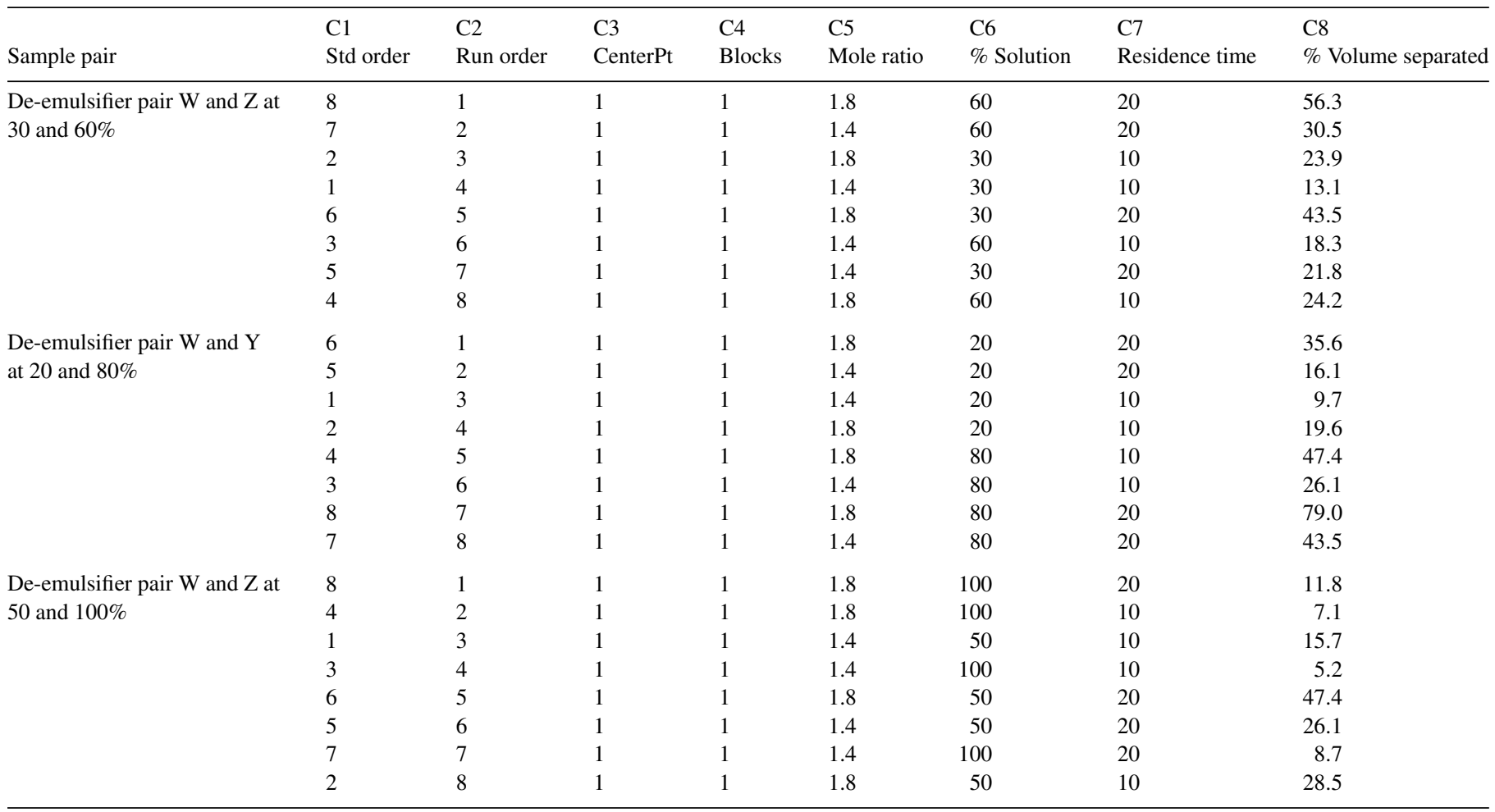

(A) and residence time, significantly influenced deemulsification with de-emulsifier concentration producing the greatest effect followed by mole ratio and residence time produced the least effect. From Table 3 and Fig. 2 the optimized values for effective de-emulsification would include mole ratio (P:F) of 1:1.5, residence time of $20 \mathrm{~min}, \%$ concentration (v/v) of de-emulsifier in xylene $80 \%$. The optimized values separated more water $(51.6 \%)$ from the crude oil emulsion system.

3.2.1.2. Normal plot of effects. Normal plots help to show which factors have significant effects on the response (volume of water separated) during the de-emulsification process. A normal effects plot is used to compare the relative magnitude and the statistical significance of both main and interaction effects. The factors that have significant effects are shown in red and the ones without significant effects are shown in black. The farther a factor is from the line, the more significant effect it has on the corresponding response. The factors falling on the line are statistically not significant.

In Fig. 4, for the volume data, there are two significant effects $(\alpha=0.5)$ and they include mole ratio (A) and residence time (C). While mole ratio had the greatest effect on the deemulsification, followed by the residence time, the de-emulsifier concentration (B) did not produce any significant effect on the de-emulsification. In Fig. 6, only nominal significant effect (7.5) on the de-emulsification process was produced by mole ratio. While residence time did not produce any significant effect, the de-emulsifier concentration pair (50 and 100\%) was counterproductive (negative effect at -12 ); whereas in Fig. 5, all three factors - mole ratio (A), de-emulsifier concentration (B)

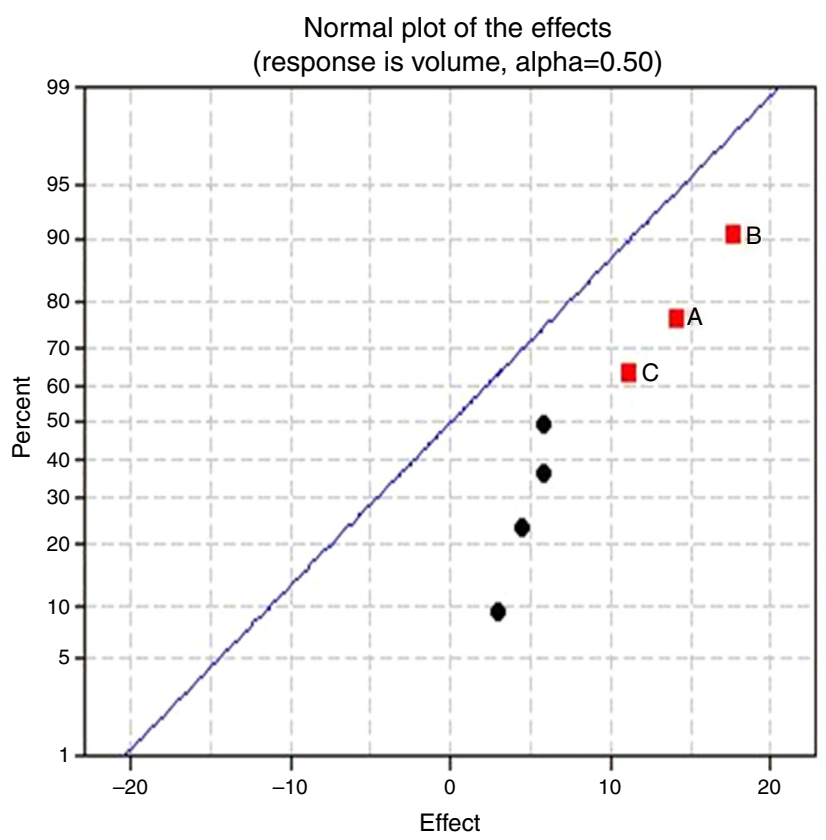

Lenth's PSE $=8775$
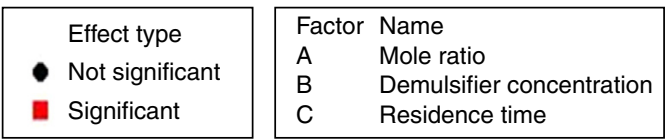

Fig. 5. Normal plot for de-emulsifier pair $\mathrm{U}$ and $\mathrm{X}$ at 20 and $80 \%$ concentrations. 


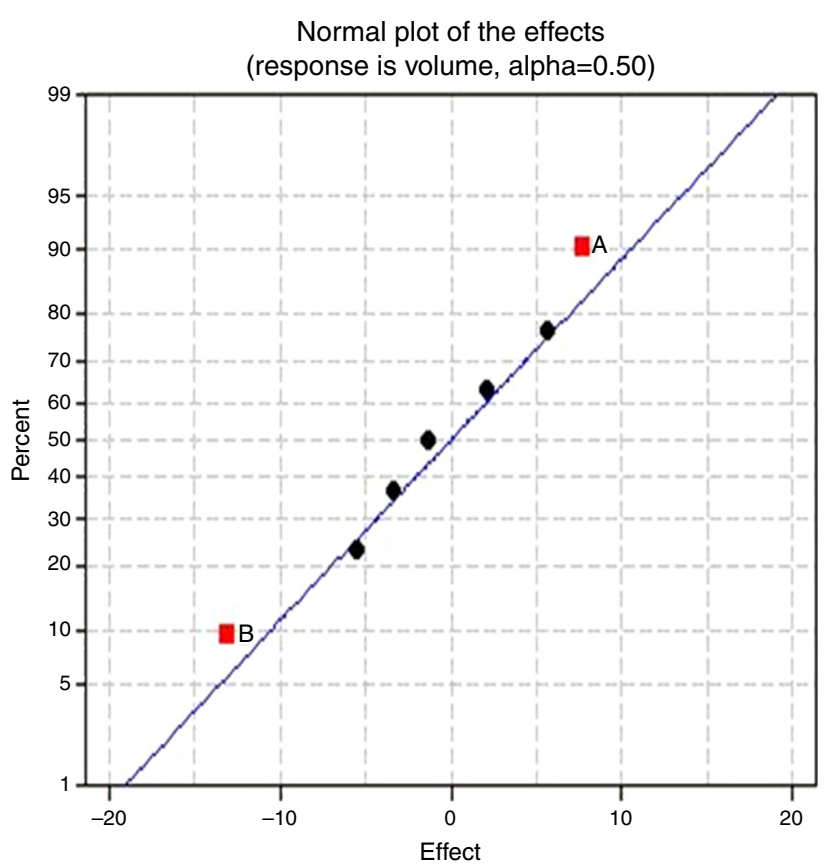

Lenth's PSE=82 125

\begin{tabular}{|l|ll|}
\hline Effect type & Factor & Name \\
- Not significant & A & Mole ratio \\
B & Demulsifier concentration \\
Significant & C & Residence time \\
\hline
\end{tabular}

Fig. 6. Normal plot for de-emulsifier pair $\mathrm{U}$ and $\mathrm{X}$ at 50 and $100 \%$ concentrations.

and residence time $(\mathrm{C})$ produced significant effects on the deemulsification process. B had the most significant effect (17.5) followed by A (14) and C (11) the least (Fig. 5).

3.2.1.3. Main effects plot. The main effect occurs when there is a consistent trend among the different levels of a factor, the plots can be used to show how response (the volume of water separarted) relates to one or more factors. A main effect is present when the change in the mean response across the levels of a factor is significant. A horizontal line (parallel to the $x$-axis) means there is no main effect present and a line that is not horizontal means there may be a main effect present. The greater the slope of the line, the stronger the effect produced on the de-emulsification.

Figs. 7-9 show the main effects of the three factors on the de-emulsification. Except for Fig. 9, where the de-emulsifier concentrations $(50 \%$ and $100 \%)$ showed a decreasing effect (negative slope) on the de-emulsification, Figs. 7 and 8 showed increasing effects (positive slope) on the de-emulsification. The implication of this is that as the mole ratio (P:F) is increased from 1:1.2 to 1:1.5, the residence time increased from 10 to $20 \mathrm{~min}$, and the de-emulsifier concentration increased from 30 to $60 \%$, their main effects on the de-emulsification also increased at different relative magnitudes. The mole ratio produced the largest effect (24) followed by the residence time (22) and the de-emulsifier concentration (20) the least. The same trend was observed in Fig. 8 but the greatest main effects were produced here than in Figs. 7 and 9. The de-emulsifier concentration

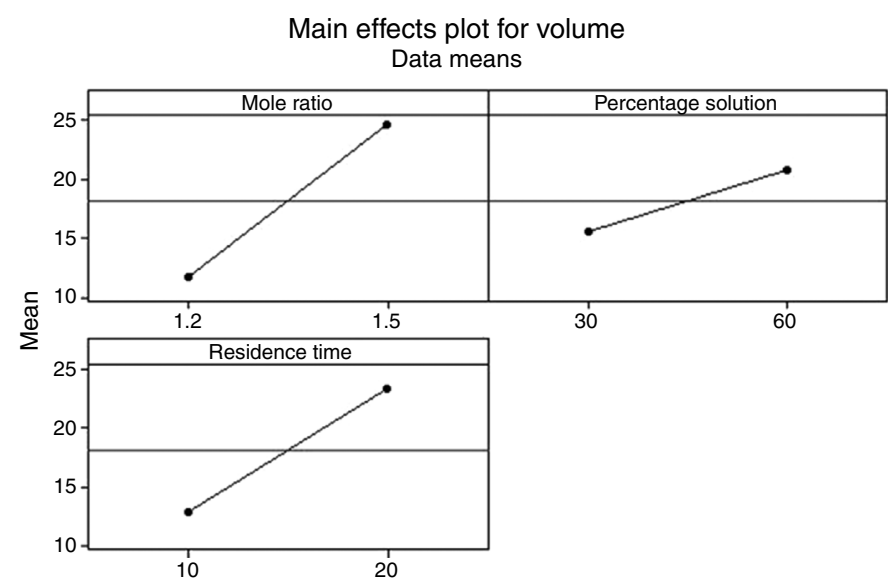

Fig. 7. Main effects plot of de-emulsifier $U$ and $X$ at 30 and $60 \%$ concentrations.

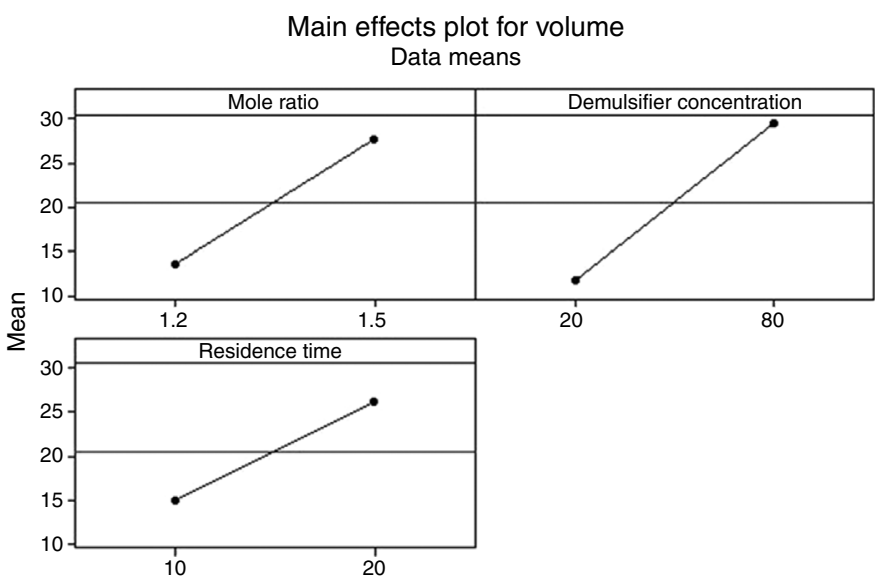

Fig. 8. Main effects plot of de-emulsifier $\mathrm{U}$ and $\mathrm{X}$ at 20 and $80 \%$ concentrations.

produced the largest effect (30) followed by the mole ratio (28) and the residence time (25) the least. Whereas, in Fig. 9, the main effects obtained are mole ratio (15), residence time (14) while the de-emulsifier concentration produced negative slope meaning that as the concentration of de-emulsifier is decreased from

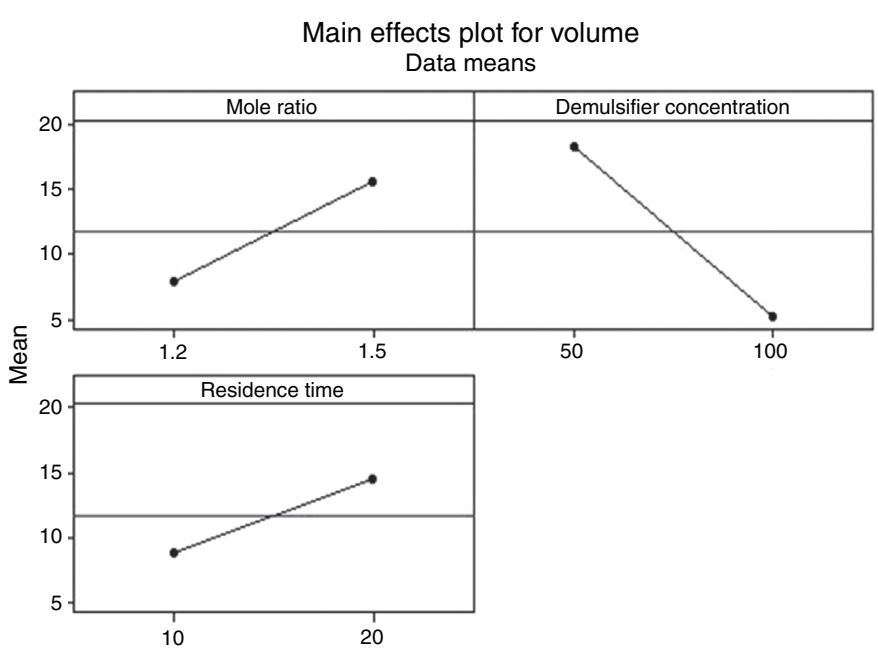

Fig. 9. Main effects plot of de-emulsifier pair $\mathrm{U}$ and $\mathrm{X}$ at 50 and $100 \%$ concentrations. 


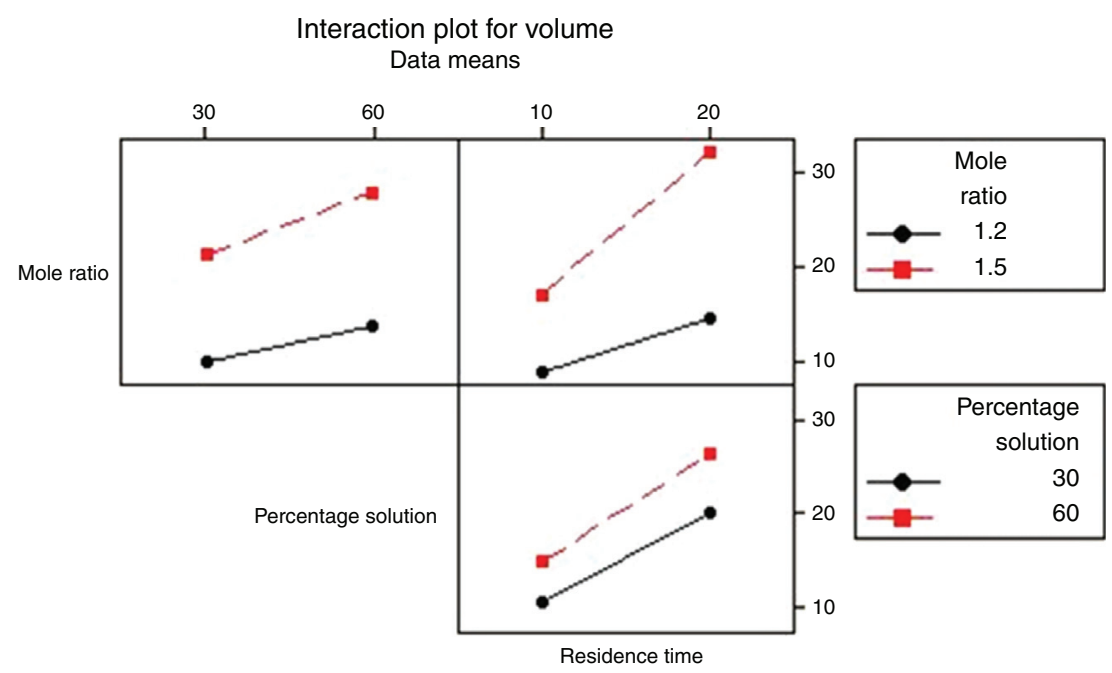

Fig. 10. Interaction plot for de-emulsifier pair $\mathrm{U}$ and $\mathrm{X}$ at 30 and $60 \%$ concentrations.

100 to $50 \%$, the main effect correspondingly increased from 5 to 19 .

Thus an optimized set of condition for the de-emulsification of the crude oil sample is to use $80 \%$ de-emulsifier concentration, $1: 1.5$ mole ratio $(\mathrm{P}: \mathrm{F})$ and residence time of $20 \mathrm{~min}$.

\subsubsection{Interaction plot. An interactions plot is used to visual-} ize the interaction effect of two factors on the response (volume of water separated) and to compare the relative strength of the effects. Minitab draws an interaction plot for two factors, or a matrix of plots for three or more factors. For each combination of factors, Minitab plots the response and joins the points for the low and high level of the factor plotted on the $x$-axis. The lines connecting the factor levels determine the presence or absence of interaction between factors. An interaction is present when the change in the response mean from the low to the high level of a factor depends on the level of a second factor. An interaction can be spotted in the graphs because when there are lines that are not parallel, an interaction is present. Generally, the greater the degree of departure from being parallel, the stronger the effect of the interacting factors.

In Fig. 10 the lines are slightly parallel to each other in the mole ratio - de-emulsifier concentration plot and de-emulsifier concentration - residence time plot. This implies that there is no interaction present. However, in the residence time-mole ratio plot, the lines are not parallel to each other; there may be an interaction present. This means that at higher mole ratio, the volume of water separated, increases as residence time increases. The interaction effect produced is about 20 from the plot. Also, in Fig. 11, the lines are slightly not parallel to each other in the 3 plots, mole ratio-residence time plot, de-emulsifier concentration-residence time plot and the mole ratio-de-emulsifier concentration plot. This implies there is interaction present. For the mole ratio-residence time plot (interaction effect 37), at high and low mole ratios, volume of water separated increases as the residence time increases. For the de-emulsifier concentration-residence time plot (interaction effect 38), at high and low de-emulsifier concentrations,

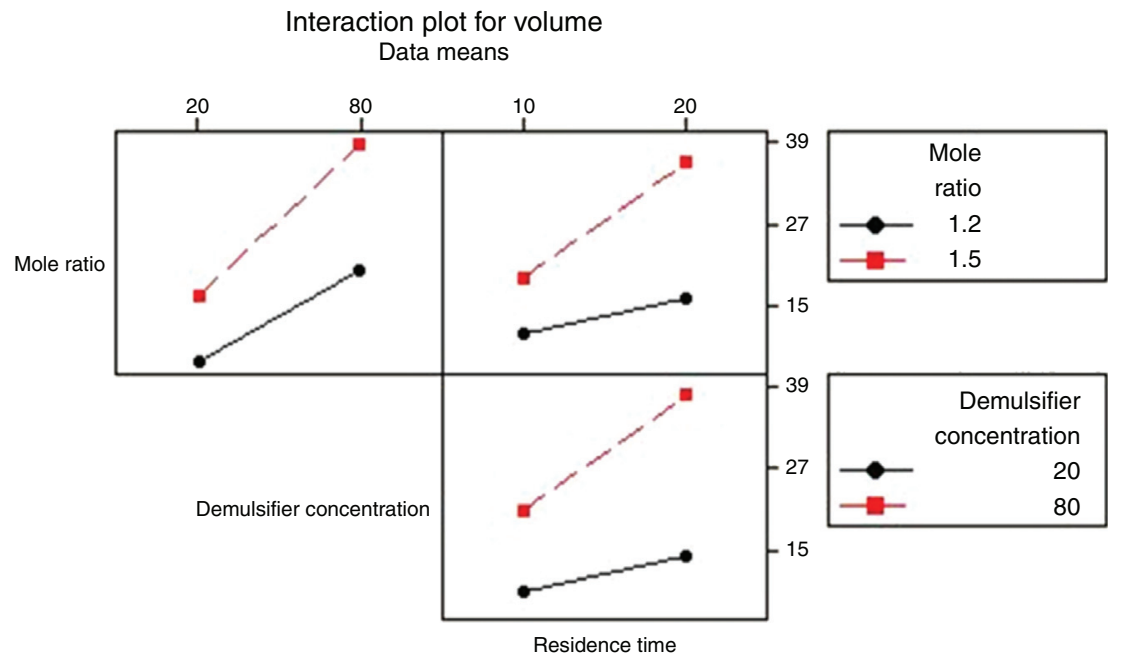

Fig. 11. Interaction plot for de-emulsifier $\mathrm{U}$ and $\mathrm{X}$ at 20 and $80 \%$ concentrations. 


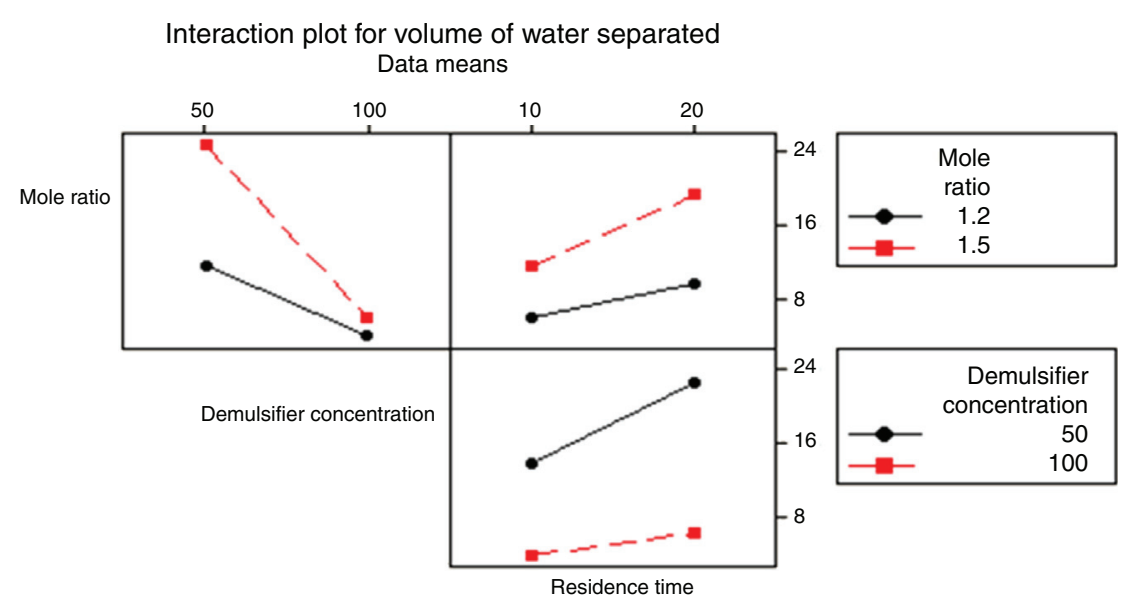

Fig. 12. Interaction plot of de-emulsifier pair $U$ and $X$ at 50 and $100 \%$ concentrations.

volume of water separated increases as residence time increases also. And for the mole ratio-de-emulsifier concentration plot (interaction effect 39), at high/low mole ratio, the volume of water separated increases as de-emulsifier concentration increases. And in Fig. 12, the lines are slightly parallel to each other in the mole ratio-residence time plot and de-emulsifier concentration-residence time plot. This implies there is no interaction present. However, in the mole ratio-de-emulsifier concentration plot, the lines are not parallel to each other; hence there is interaction present (interaction effect is 21 ). The lines have negative slope. This means that at higher mole ratio, the volume of water separated, decreases as de-emulsifier concentration increases. And at low mole ratio, the volume of water decreases as de-emulsifier concentration increases.

Thus from Fig. 11, the best conditions for de-emulsification of the crude oil emulsion sample using de-emulsifier pair $U$ and $\mathrm{X}$ are: mole ratio (P:F) of 1:1.5, de-emulsifier concentration $80 \%$ and residence time of $20 \mathrm{~min}$.

\subsubsection{Analysis of de-emulsifier pair $V$ and $Y$}

3.2.2.1. Pareto chart. As discussed in the preceding section, a Pareto chart is used to know which factors have statistically significant effects on the response. The charts are presented below.

From Fig. 13, it was observed that four factors were statistically significant and they include mole ratio, concentration of the de-emulsifier, residence time and mole ratio by residence time interaction. The largest effect (17) on the de-emulsification process was produced by mole ratio. The next significant effect (12.5) was followed by the residence time, 6.5 produced by deemulsifier concentration and 3.8 produced by the interaction of mole ratio-residence time. From Fig. 14, three factors are statistically significant. These factors and their effects include de-emulsifier concentration producing the largest effect (23.5) on the de-emulsification process followed by mole fraction effect (22.6) and residence time effect (14.5). From Fig. 15, the results obtained at de-emulsifier concentration $50 \%$ and $100 \%$ follow the same trend as in Figs. 13 and 14. The de-emulsifier concentration and mole ratio have significant effects, but de-emulsifier concentration had greater effect (17) in the de-emulsification process than mole ratio effect (9.3).

Hence from the results obtained the best conditions for effecting de-emulsification of the crude oil emulsion using the de-emulsifier pair V and Y would be at $80 \%$ de-emulsifier concentration, mole ratio of 1.7 and residence time of $20 \mathrm{~min}$.

3.2.2.2. Normal, main and interaction plots of effects of deemulsifier pair $V$ and $Y$. These followed exactly the same trend as presented in previous sections. It was found that the best water separation using de-emulsifier pair $\mathrm{V}$ and $\mathrm{Y}$ could be obtained at $80 \%$ concentration, mole ratio of 1.7 and residence time of $20 \mathrm{~min}$. These results were corroborated by results presented in Table 4 . The highest water separation $67.7 \%$ was obtained from

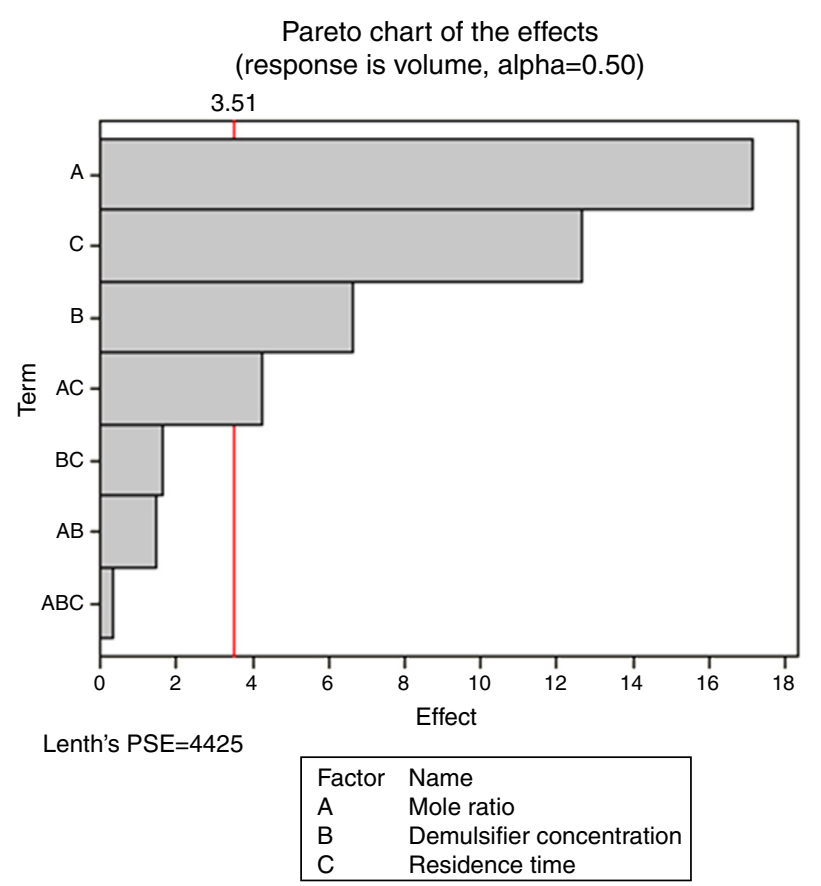

Fig. 13. Pareto chart for de-emulsifier pair $\mathrm{V}$ and $\mathrm{Y}$ at 30 and $60 \%$ concentrations. 


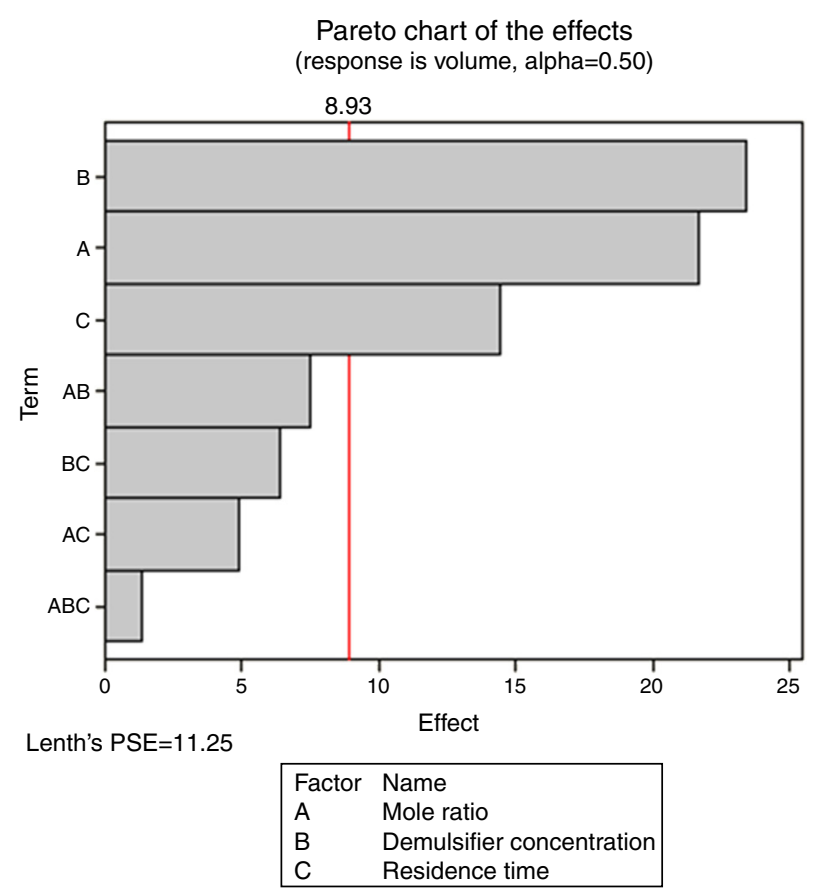

Fig. 14. Pareto chart for de-emulsifier pair V and $\mathrm{Y}$ at 20 and $80 \%$ concentrations.

Table 4 at mole ratio P:F (1:1.7), de-emulsifier concentration of $80 \%$ and residence time of $20 \mathrm{~min}$. This was followed by the $47.4 \%$ water separation obtained from Table 4 at the same mole ratio P:F (1:1.7), residence time (20 $\mathrm{min})$ but at a different deemulsifier concentration of $60 \%$. The least water separation of $40.6 \%$ was obtained from Table 4 also at the same mole ratio P:F (1:1.7) and residence time (20 min) but at a different deemulsifier concentration of $50 \%$.

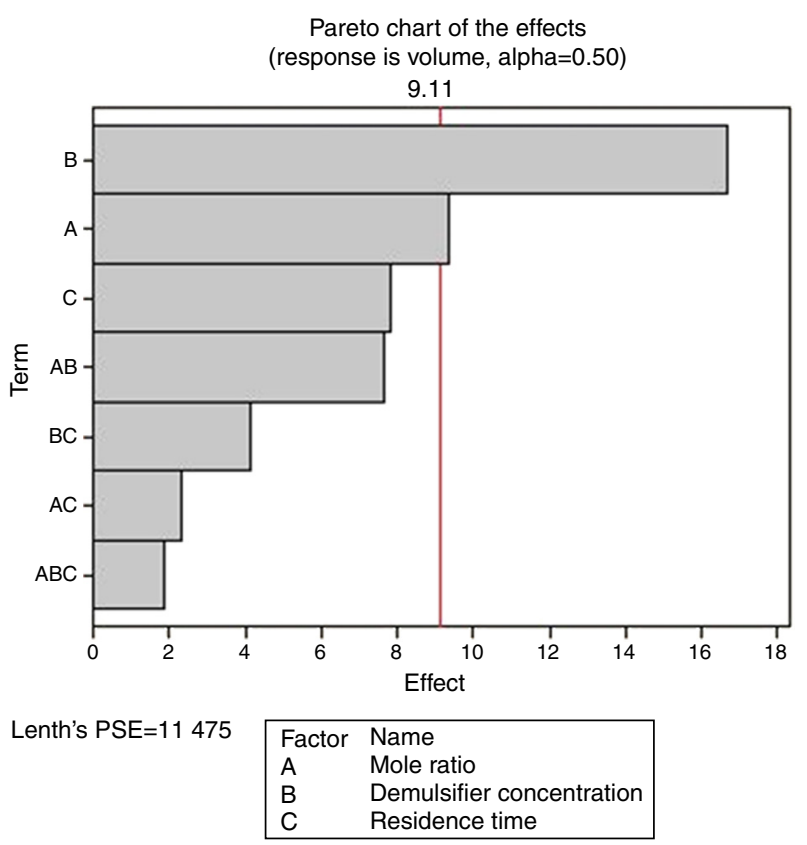

Fig. 15. Pareto plot for de-emulsifier pair V and Y at 50 and 100\% concentrations.

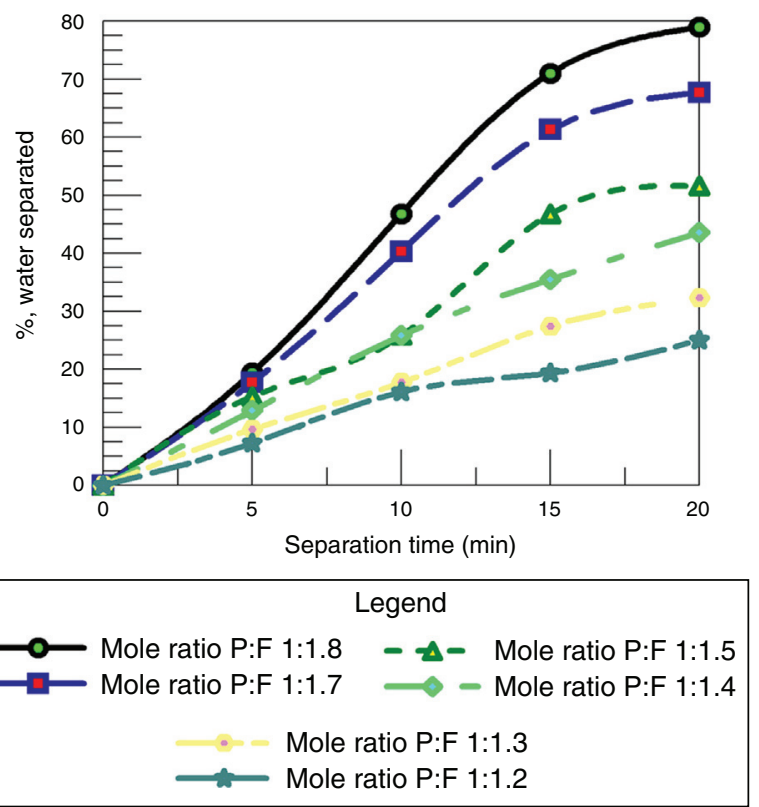

Fig. 16. Effects of mole ratio P:F of $80 \%$ de-emulsifier solution in xylene in de-emulsification.

\subsubsection{Pareto, normal, main and interaction plots of effects of de-emulsifier pair $W$ and $Z$}

The method of analyses of results presented in the previous sections also applies to the de-emulsifier pair $\mathrm{W}$ and $\mathrm{Z}$. The results obtained here, essentially followed the same trend as the previous. And it was found that the best water separation using the de-emulsifier pair $\mathrm{W}$ and $\mathrm{Z}$ could be obtained at $80 \%$ concentration, mole ratio of 1.8 and residence time of $20 \mathrm{~min}$. These results were also corroborated by results presented in Table 5 . The highest water separation of 79\% was obtained from Table 5 at mole ratio P:F (1:1.8), de-emulsifier concentration of $80 \%$ and residence time of $20 \mathrm{~min}$. This was followed by the $55.3 \%$ water separation obtained from Table 5 at the same mole ratio P:F (1:1.8), residence time (20 $\mathrm{min})$ but at a different de-emulsifier concentration of $60 \%$. The least water separation of $50 \%$ was obtained from Table 5 also at the same mole ratio P:F (1:1.8) and residence time (20 $\mathrm{min}$ ) but at a different de-emulsifier concentration of $50 \%$.

From the preceding three sections, it is seen that the deemulsifier pair $\mathrm{W}$ and $\mathrm{Z}$, when compared to de-emulsifier pairs $(\mathrm{U} \& \mathrm{X})$ and $(\mathrm{V} \& \mathrm{Y})$ gave the best overall water separation of $79 \%$ at mole ratio (P:F) 1:1.8, de-emulsifier concentration of $80 \%$ and residence time of $20 \mathrm{~min}$. For the range of de-emulsifier concentration pair $30 \& 60 \%, 20 \& 80 \%$ and $50 \& 100 \%$ investigated, the pair of 20 and $80 \%$ concentration gave the best water separation all through the experimental work. These findings are further explained in Sections 3.2.4 and 3.2.5.

\subsubsection{Effect of molar ratio of $F / P$ for resole in de-emulsification process}

As shown in Fig. 16, it can be seen that as the mole ratio of the F:P increases, the volume of water removed increases. The reason is that resins (resoles) with high mole ratio of F:P have higher methyl-ol content hence higher solubility in water compared to 

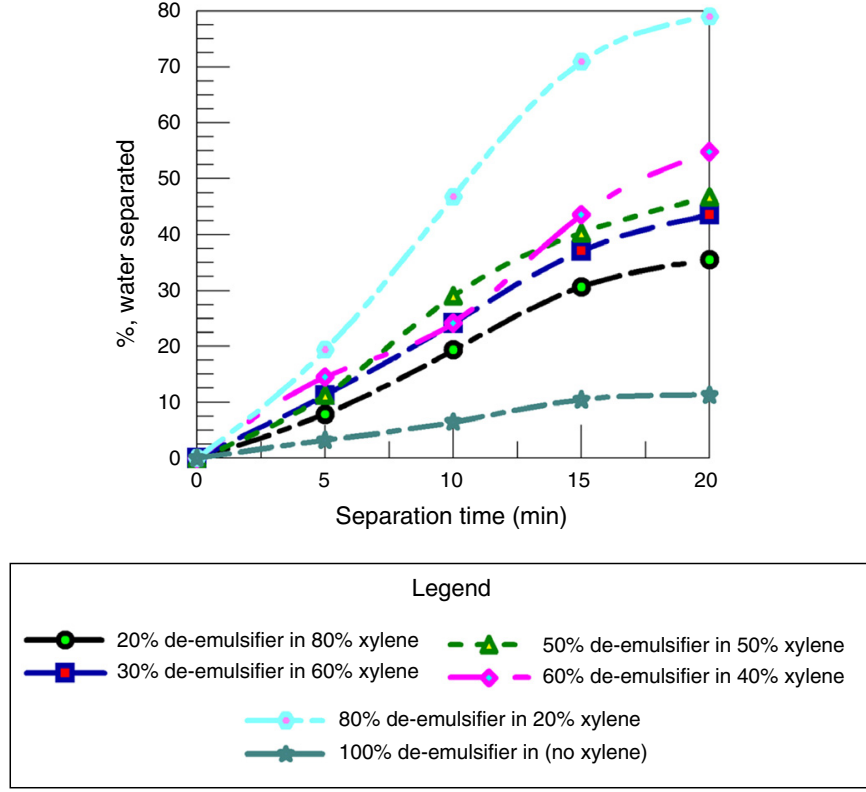

Fig. 17. Effect of adding xylene to de-emulsifier on water separation efficiency at different concentrations.

those in the intermediate and low content of formaldehyde. This further confirms the result from each of the pairs earlier considered in which the de-emulsifier with the higher mole ratio was the optimum de-emulsifier for water separation. This shows that at a high formaldehyde to phenol ratio of a de-emulsifier, the more the volume of water removed in the de-emulsification process than at a lower F:P ratio.

Therefore the optimum de-emulsifier amongst the resoles will be de-emulsifier $\mathrm{Z}$ with F:P ratio of 1.8:1. Comparing this to studies carried out by other researchers Temple-Heald, Davies, Wilson, and Readman (2015); Al-Sabagh, Noor ElDin, Abo-El Fotouh, and Nasser (2009); Pena, Hirasaki, and Miller (2005), where base catalyzed ethoxylated phenolic resins were investigated, the phenolic resins promoted coalescence of droplets (water separation) giving optimum performance of the de-emulsifiers as their hydrophilic property (or water solubility) and molecular weight (mole ratios) were increased.

\subsubsection{Effect of solvents on water separation efficiency}

The effect of adding solvents to the de-emulsifier to investigate the water separation efficiency was carried out by using xylene. Xylene was used as a modifying solvent or agent to enhance the performance of de-emulsifiers.

Fig. 17 shows the effect of adding different quantities of xylene to varied quantities of de-emulsifiers and testing their water separation efficiency. Fig. 17 shows that the water separation efficiency increases with decreasing the amount of xylene added. A maximum water separation of $79 \%$ was obtained at concentration (20\% xylene in $80 \%$ de-emulsifier), 20 min and F:P mole ratio of 1.8:1. These results are in agreement with the results obtained by Hamadi and Mahmood (2010).

Fig. 18 shows a comparison between using the de-emulsifier with and without the addition of xylene. It was observed that the water separation obtained was $79 \%$ when xylene was used as

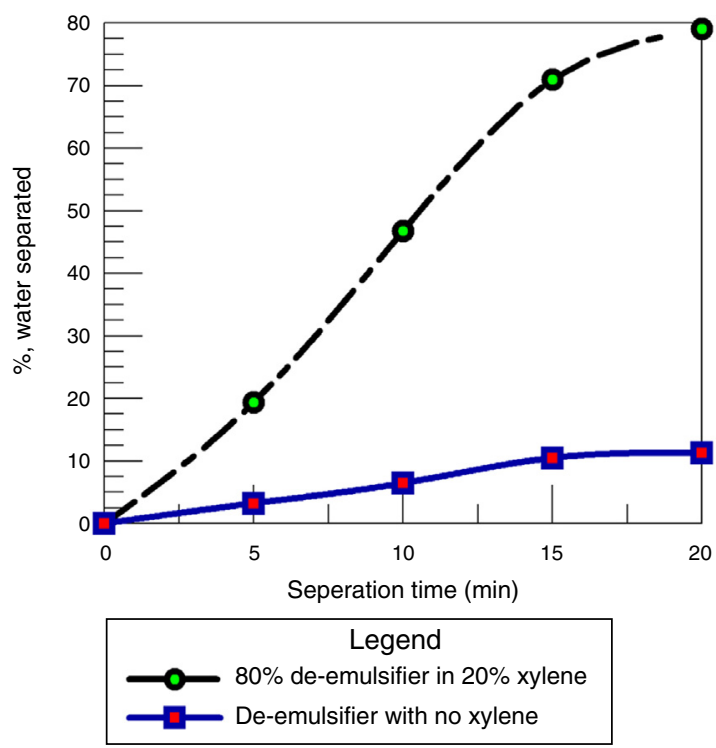

Fig. 18. Comparison between the extent of water separation of de-emulsifier with and without xylene.

solvent for the de-emulsifier while only $11.9 \%$ was obtained when the de-emulsifier was used without xylene. This is because the solvent carries the de-emulsifying agent to the oil/water interface much faster than how it would occur without its presence. At the interface, the de-emulsifier solution in xylene readily goes in the oil phase of the emulsion resulting in lower interfacial tension and the eventual rupturing of the film to effect emulsion separation. These results are in agreement with the results obtained by Djuve et al. (2001); Kokal and Al-Juraid (1999).

\subsubsection{Comparison of commercial de-emulsifier and} formulated de-emulsifier sample $Z$

The de-emulsifier $\mathrm{Z}$ at $80 \%$ concentration, mole ratio 1.8 , residence time $20 \mathrm{~min}$ and dosage at $50 \mathrm{ppm}$ gives the optimized conditions. It removed $79 \%$ of water from the crude oil
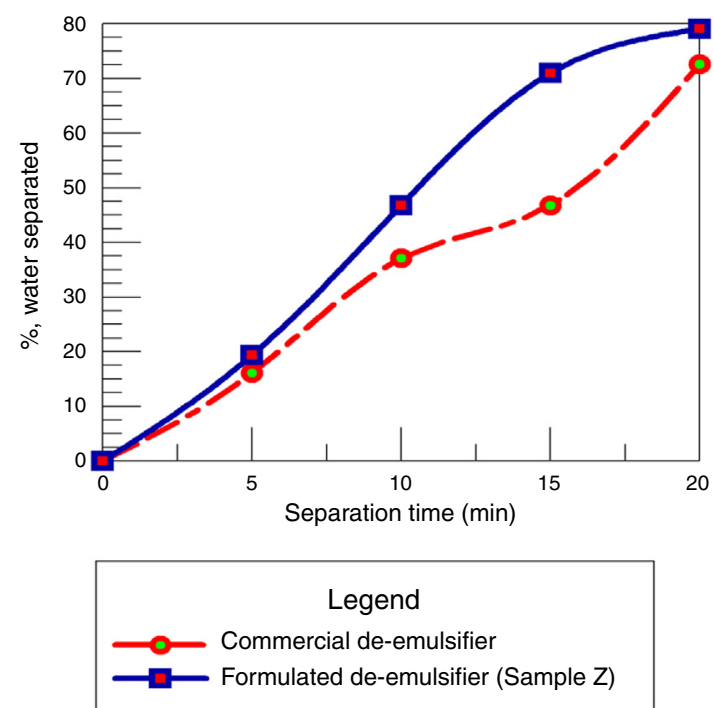

Fig. 19. Comparison between the best formulated de-emulsifier and commercial de-emulsifier. 
emulsion sample while the commercial de-emulsifier removed $71 \%$ of water from the emulsion sample at the same conditions. Hence the formulated de-emulsifier $\mathrm{Z}$ performed better than the commercial de-emulsifier since the principal criterion for determining the best emulsion resolution is by the degree of water separation achieved using a chemical de-emulsifier (see Fig. 19).

\section{Conclusion}

From the study, it is seen that the performance of the de-emulsifier increases with increasing F:P mole ratios and separation time for the formulated resoles. The performance was measured in terms of its water separation efficiency. The resole de-emulsifier solutions in xylene were seen to enhance their water separation ability at all concentrations compared to the same de-emulsifiers used without xylene. The best single de-emulsifier is sample $\mathrm{Z}$ formulated with $\mathrm{F}: \mathrm{P}$ ratio of 1.8:1 at de-emulsifier concentration of $80 \%$ in $20 \%$ xylene solvent. This produced as high as $79 \%$ water separation efficiency, an improvement over the commercial de-emulsifier sample which gave $71 \%$ at the same conditions. The reduction of the active deemulsifier component during the de-emulsification process will invariably lead to a reduced cost of de-emulsifiers when used in the Nigerian petroleum industry and will further boost the local content initiative of the Federal Government. 20\% of xylene content gave the optimal percentage water separation. Above the optimal xylene content, lower percentage water separation or decreasing performance of the de-emulsifiers results.

\section{Conflict of interest}

The authors have no conflicts of interest to declare.

\section{Acknowledgement}

The authors gratefully acknowledge the financial support received from the Management of Covenant University which was of great help to undertake this research work.

\section{References}

Akinyemi, O. P., Udonne, J. D., Efeovbokhan, V. E., \& Ayoola, A. A. (2016). A study on the use of plant seed oils, triethanolamine and xylene as flow improvers of Nigerian waxy crude oil. Journal of Applied Research and Technology, 14, 195-205.

Al-Sabagh, A. M., Noor El-Din, M. R., Abo-El Fotouh, S., \& Nasser, N. M. (2009). Investigation of the demulsification efficiency of some ethoxylated polyalkylphenol formaldehydes based on locally obtained materials to resolve water-in-oil emulsions. Journal of Dispersion Science and Technology, 30(2), 267-276.

Aske, N. (2002). Ph.D Thesis: Characterization of crude oil components, asphaltene aggregation and emulsion stability by means of near infrared spectroscopy and multivariate analysis. Norwegian University of Science and Technology. http://www.chemeng.ntnu.no/research/polymer/ ugelstadlab/thesis/naske.pdf (Accessed December 28, 2015)

Becher, P. (1985). Encyclopedia of emulsion technology. (Vol. 2). Applications New York, NY 10016: Madison Ave. ISBN 0-8247-1877-1.
Bhardwaj, A., \& Hartland, S. (1998). Studies on buildup of interfacial film at the crude oil/water interface. Journal of Dispersion Science Technology, 19(4), 465-473.

Dickson, U. J., \& Udoessien, E. I. (2012). Physicochemical studies of Nigeria's crude oil blends. Petroleum \& Coal, 54(3), 243-251.

Djuve, J., Yang, X., Fjellanger, I. J., Sjoblom, J., \& Pelizzetti, E. (2001). Chemical destabilization of crude oil-based emulsions and asphaltene stabilized emulsions. Colloid \& Polymer Science, 279, 232-239.

Easton, T., \& Thomas, B. (1989). De-emulsification of oils. United States Patent 888107.

Efeovbokhan, V. E., Olayemi, K. M., Anawe, P. A. L., \& Abatan, O. G. (2015). Optimization of phenolic-based de-emulsifiers. Journal of Applied Science, 15(6), 862-873.

Grace, R. (1992). Commercial Emulsion Breaking. In L. L. Schramm (Ed.), Emulsions. Fundamentals and applications in the petroleum industry (pp. 313-338). Washington, DC: American Chemical Society.

Hamadi, A. S., \& Mahmood, L. H. (2010). Demulsifiers for simulated Basrah crude oil. Engineering and Technology Journal, 28(1), 54-64.

Kokal, S., \& Al-Juraid, J. (1999). Quantification of various factors affecting emulsion stability: Water cut, temperature, shear, asphaltene content, deemulsifier dosage and mixing different crudes. In Proceedings of the society of petroleum engineers annual technical conference and exhibition.

Kokal, S., Al-Yousif, A., \& Meeranpillai, N. S. (2001). Very thick crude emulsions: a field case study of a unique crude production problem. In Presented at the SPE annual technical conference and exhibition.

Myers, D. (1992). Surfactant science and technology. Weinheim, NY: VCH. ISBN 3-527-89586-8.

NNPC. (2015). Oil production.. http://nnpcgroup.com/NNPCBusiness/Upstream Ventures /OilProduction.aspx/ (Accessed March 13, 2015)

Onojake, M. C., Osuji, L. C., \& Oforka, N. C. (2013). Preliminary hydrocarbon analysis of crude oils from Umutu/Bomu fields, south west Niger Delta Nigeria. Egyptian Journal of Petroleum, 22(2), 217-224.

Oyekunle, L. O., \& Famakin, O. A. (2004). Studies on Nigerian crudes, characterization of crude oil mixtures. Petroleum Science and Technology, 22(5), 665-675.

Pena, A. A., Hirasaki, G. J., \& Miller, C. A. (2005). Chemically induced destabilization of water-in-crude oil emulsions. Industrial \& Engineering Chemistry Research, 44, 1139-1149.

Porter, M. R. (1994). Use of surfactant theory: Handbook of surfactants. pp. 26-93. United Kingdom: Blackie Academic \& Professional. ISBN: 978-07514-0170-7.

Sawyer, C. N., McCarty, P. L., \& Parkin, G. F. (1994). Chemistry for environmental engineering (4th ed., pp. 26-93). United Kingdom: McGraw Hill, Academic \& Professional., 1SBN, 0-07-119888-1 (ISE).

Selvarajan, R., Sivakumar, A., \& Marble, R. A. (2001). Aqueous dispersion of an oil soluble demulsifier for breaking crude oil emulsions. US Patent No. 6,294,093, http://www.google.com/patents/US6294093?cl=un.

Staiss, F., Bohm, R., \& Kupfer, R. (1991). Improved demulsifier chemistry: A novel approach in the dehydration of crude oil. Society of Petroleum Engineers, Production Engineering, 6(3), 334-338, http://dx.doi.org/10.2118/18481-PA

Sunil, L. K. (2006). Crude oil emulsions, Petroleum engineering handbook (Vol. 1). Saudi Aramco. SPE document.

Tambe, D. E., \& Sharma, M. K. (1993). Factors controlling the stability of colloid-stabilized emulsions: An experimental investigation. Journal of Colloid and Interface Science, 157(1), 244-253. http://dx.doi.org/ 10.1006/jcis. 1993.1182

Temple-Heald, C., Davies, C., Wilson, N., \& Readman, N. (2015). Developing new surfactant chemistry for breaking emulsions in heavy oil. Journal of Petroleum Technology, 66, 30-36.

Yasin, G., Bhanger, B. I., Ansari, Naqvi, S. M., Ashraf, M., Ahmad, K., \& Talpur, F. N. (2013). Quality and chemistry of crude oils. Journal of Petroleum Technology and Alternative Fuels, 4(3), 53-63. 